\title{
ARTICLE
}

\section{A functional BH3 domain in an aquaporin from Leishmania}

\section{infantum}

\author{
CM Genes ${ }^{1,5}, \mathrm{H}$ de Lucio ${ }^{1,5}$, VM González ${ }^{2}$, PA Sánchez-Murcia ${ }^{3}, \mathrm{E} \mathrm{Rico}^{1}, \mathrm{~F} \mathrm{Gago}^{3}, \mathrm{~N} \mathrm{Fasel}^{4}$ and A Jiménez-Ruiz $^{1}$
}

Despite the absence of sequences showing significant similarity to any of the members of the $\mathrm{Bcl}-2$ family of proteins in protozoa, experiments carried out in yeast or trypanosomatids have demonstrated that ectopic expression of some of these members alters their response to different death stimuli. Because the BH3 domain is the smallest common signature in all the proteins of this family of apoptosis regulators and also because they are essential for molecular interactions between antagonistic members, we looked for sequences with significant similarity to the $\mathrm{BH} 3$ motif in the Leishmania infantum genome. Among the top scoring ones, we found the MYLALQNLGDEV amino-acid stretch at the $C$ terminus of a previously described aquaporin, now renamed as Li-BH3AQP. This motif is highly conserved in homologous proteins from other species of the Leishmania genus. The association of Li-BH3AQP with human $\mathrm{BCl}-\mathrm{X}_{\mathrm{L}}$ was demonstrated by both co-immunoprecipitation and yeast two-hybrid experiments. Ectopic expression of Li-BH3AQP reduced viability of HeLa cells and this deleterious effect was abrogated by the simultaneous overexpression of Bcl- $\mathrm{X}_{\mathrm{L}}$. Although we were not able to demonstrate a reduction in parasite viability when the protein was overexpressed in Leishmania promastigotes, a prodeath effect could be observed when the parasites overexpressing Li-BH3AQP were treated with staurosporine or antimycin A. Surprisingly, these parasites were more resistant, compared with wild-type parasites, to hypotonic stress or nutrient deprivation. The prodeath activity was abolished upon replacement of two highly conserved amino acids in this BH3 domain. Taken together, these results point to $\mathrm{Li}-\mathrm{BH} 3 \mathrm{AQP}$ as the first non-enzymatic protein ever described in trypanosomatids that is involved in cell death.

Cell Death Discovery (2016) 2, 16043; doi:10.1038/cddiscovery.2016.43; published online 4 July 2016

Research in the field of cell death processes in unicellular parasites displaying features normally associated with apoptosis in metazoan organisms has generated a significant body of literature since the first description in 1996. ${ }^{1,2}$ Biochemical and morphological features resembling this cell death process have been described across yeasts, ${ }^{3}$ algae $^{4}$ and the genera Trypanosoma, ${ }^{1,2,5}$ Leishmania $^{6,7}$ and Plasmodium. $^{8-11}$ The occurrence of apoptosis in unicellular organisms is a challenge for evolutionary theory, as it seems to argue against the Darwinian notion of 'survival of the fittest'. However, promoting the reproductive success of relatives with a very similar genetic content, such as those resulting from infections of the host with a very low number of parasites, may be a successful strategy to ensure transmission of copies of their genes to future generations. $^{12}$ Thus, programmed cell death (PCD) processes might be useful to regulate parasite density inside the host and aid in avoiding inflammatory responses from the immune system, thereby facilitating a sustained infection. ${ }^{13}$ Nevertheless, the almost absolute absence of dedicated molecular pathways that coordinate this process in single-celled organisms is still a major concern that hampers acceptance of the existence of PCD in parasites. ${ }^{14}$ With the exception of endonucleases $\mathrm{G}^{15-17}$ and metacaspases, ${ }^{18-20}$ no other molecule has been implicated in PCD in protozoans.

In this scenario, it is conspicuous that, with a single exception, no coding sequence for any member of the Bcl-2 family has been found to date in the genomic databases of protozoa. It is therefore intriguing that mammalian $\mathrm{Bcl}-2$ proteins can inhibit (e.g. $\mathrm{Bcl}-\mathrm{X}_{\mathrm{L}}$ ) or induce (e.g. Bax) cell death processes when expressed in yeast, ${ }^{21,22}$ or Leishmania cells. ${ }^{7,23}$ Up till now, the yeast proapoptotic $\mathrm{BH} 3-$ only protein $\mathrm{Ybh} 3 \mathrm{p}$ is the unique $\mathrm{Bcl}-2$ family member described in the literature for unicellular organisms. Overexpression of Ybh3p facilitates apoptosis induced by a variety of stimuli, whereas its ablation inhibits death and increases replicative lifespan. ${ }^{24}$ Similar to other mammalian $\mathrm{BH} 3$-only proteins, Ybh3p translocates to mitochondria during apoptosis, triggering their depolarization and cytochrome $c$ release.

$\mathrm{BCl}$-2-related proteins share homology in one or several of the four regions designated as the $\mathrm{BCl}-2$ homology $(\mathrm{BH})$ domains $\mathrm{BH} 1$, $\mathrm{BH} 2, \mathrm{BH} 3$ and $\mathrm{BH} 4$. Among them, only $\mathrm{BH} 3$ is consistently found in all members of the family, as it is essential for binding associations between pro- and antiapoptotic members. Owing to the demonstrated effect of ectopic expression of members of the mammalian $\mathrm{Bcl}-2$ family of proteins in Leishmania parasites, we initiated a search for putative $\mathrm{BH} 3$-coding sequences in the Leishmania infantum genome. This strategy allowed us to identify a $\mathrm{BH} 3$ domain in a protein previously annotated as an aquaporin. We then examined the ability of this protein to bind to $\mathrm{BCl}-\mathrm{X}_{\mathrm{L}}$ and its effects on viability of both HeLa cells and $L$. infantum promastigotes.

\section{RESULTS}

$\mathrm{BH} 3$ domains in $L$. infantum

Previous results from our laboratory demonstrated that ectopic expression of human $B c l-X_{L}$ in $L$. infantum reduces the death rate

\footnotetext{
${ }^{1}$ Departamento de Biología de Sistemas, Universidad de Alcalá, Alcalá de Henares 28805, Spain; ${ }^{2}$ Laboratory of aptamers, Departamento de Bioquímica-Investigación, IRYCIS-

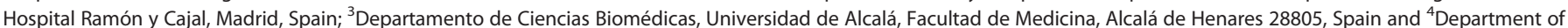
Biochemistry, University of Lausanne, 155 Chemin des Boveresses, Epalinges 1066, Switzerland.

Correspondence: A Jiménez-Ruiz (antonio.jimenez@uah.es)

${ }^{5}$ These authors contributed equally to this work.

Received 10 May 2016; accepted 15 May 2016; Edited by A Rufini
} 
of the parasites in response to heat shock. ${ }^{7}$ In an attempt to identify putative proteins able to interact with this antiapoptotic protein, we developed a bioinformatics search for DNA sequences coding for putative $\mathrm{BH} 3$ domains in the $L$. infantum genome. The PHI-BLAST (Pattern Hit Initiated BLAST) algorithm was chosen to look for non-redundant protein sequences in the Leishmania genus using the central region from the PS01259 motif signature (L-[KARQ]-x-[IVAL]-G-D-[DESG]-[LIMFV]; residues 5-12) as the search pattern. This region contains the most highly conserved residues in the $\mathrm{BH} 3$ domain. As a result, we were able to identify the sequence MYLALQNLGDEV (amino acids that fit the search pattern are underlined) at the $C$ terminus of an $L$. infantum protein previously named AQP putative (XP_001465642.1). ${ }^{25}$ This putative $\mathrm{BH} 3$ domain is completely conserved in orthologs from L. donovani (ACZ51352), L. major (XP_001683293), L. mexicana (XP_003875596), L. braziliensis (XP_001568467) and L. panamensis (XP_010702776). The sequence $\log ^{26}$ for ProSite entry PS01259 and a multiple sequence alignment of the putative $\mathrm{BH} 3$ domain from XP 001465642 and equivalent domains from different members of the $\mathrm{Bcl}-2$ family of proteins are shown in Figure 1. It can be observed that the consensus is good for all residues with the exceptions of (i) a methionine in position 1, which is usually occupied by another hydrophobic amino acid, and (ii) the lack of residues 13-15 because the valine in position 12 in this motif corresponds to the C-terminal amino acid of XP_001465642. Analysis of the sequences of members of this family of proteins in higher eukaryotes reveals that very few of them match the PS01259 pattern exactly. In fact, the recall rate (true positives/(true positives+false negatives)) is as low as $44 \%,{ }^{27}$ which reveals the absence of an absolute consensus sequence for the $\mathrm{BH} 3$ domain.

XP_001465642.1 (in common to all its orthologs in other Leishmania species) belongs to the major intrinsic protein family of proteins, which contain characteristic pore structures that are able to span the plasma membrane and allow the transport of water or small neutral solutes such as glycerol. Because of the presence of a putative $\mathrm{BH} 3$ domain, we propose to rename XP_001465642.1 to Li-BH3AQP.

Structural analysis of $\mathrm{Li}-\mathrm{BH} 3 \mathrm{AQP}$

The 3D structure of this $31 \mathrm{kDa}$ protein (294 residues long) was modeled using the crystal structures of aquaporins Aqy1 from Pichia pastoris (Pp-Aqy1, PDB entry 2W2E, 26\% sequence identity; ${ }^{28}$ Supplementary Figure S1) and AqpM from Methanothermobacter marburgensis (Mm-AqpM, PDB entry 2F2B, 29\% sequence identity; ${ }^{29}$ Supplementary Figure S1) as templates. Each monomer in Li-BH3AQP is likely to be formed by six full membrane-spanning helices (M1, M2, M4, M5, M6 and M8), two intracellular loops (IL1 and IL2) defined by residues 130-141 and 207-211, respectively, and three extracellular loops made up of residues 91-95 (EL1), 167-182 (EL2) and 252-264 (EL3) (Figure 2). In addition, each monomer presents two half-membrane-spanning helices M3 (residues 121-129) and M7 (240-249), which constitute a seventh pseudotransmembrane segment that contains the Asn-Pro-Ala (NPA) aquaporin signature motif near the center of the water channel. ${ }^{30}$ It is noteworthy than in the second motif that the Ala residue has been replaced by Met in Li-BH3AQP. The nonpolar side chains of these aliphatic residues have been shown to participate in preserving the orientation of the two asparagines in the center of the channel that are responsible for substrate selectivity ${ }^{31}$ (Figure 2). The Li-BH3AQP loops IL1, EL2 and EL3 present insertions of up to seven residues compared with Pp-Aqy1 or Mm-AqpM, and, according to our model, Cys251 and Cys260 located on EL3 are close enough to make a disulfide bond between them. Regarding the quaternary structure of the protein, Li-BH3AQP would be organized as a homotetramer within the lipid membrane with both $\mathrm{N}$ and $\mathrm{C}$ termini oriented towards the cytosol. The putative $\mathrm{BH} 3$ domain (residues 283-MYLALQNLGDEV-294), which is predicted to be structured as an $a$-helix except for the last four residues, is projected out towards the opposite face of the channel. In such a

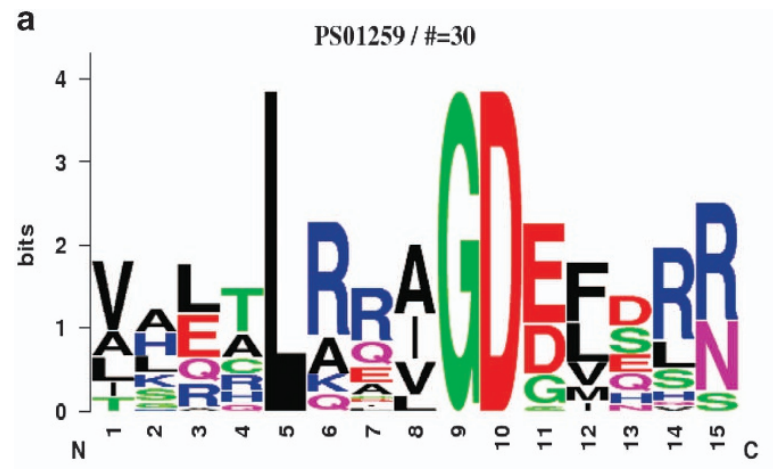

b

$\begin{array}{ll}\text { LiBH3AQP } & \text { XP 001465642.1 (Leishmania infantum) } \\ \text { YNL305cP } & \text { AAT92698.1 (Saccharomyces cerevisiae) } \\ \text { Bnip3 } & \text { NP_004043.2 (Homo sapiens) } \\ \text { Bcl-2-like protein } 1 \text { XP_003387574.1 (Amphimedon queenslandica) } \\ \text { Hrk } & \text { NP_003797.1 (Homo sapiens) } \\ \text { Mcf } & \text { CAE16514.1 (Photorhabdus luminescens) } \\ \text { PUMA } & \text { Q9BXH1.1 (Homo sapiens) } \\ \text { Bcl-xL } & \text { CAA80661.1 (Homo sapiens) } \\ \text { NOXA } & \text { Q13794.1 (Homo sapiens) } \\ \text { HyBcl-2-1ike-4 } & \text { ABS84173.1 (Hydra Vulgaris) } \\ \text { Bim } & \text { O43521.1 (Homo sapiens) } \\ \text { Bax-like } & \text { XP } 791118.3 \text { (Strongylocentrotus purpuratus) } \\ \text { Bax } & \text { Q07812.1 (Homo sapiens) }\end{array}$

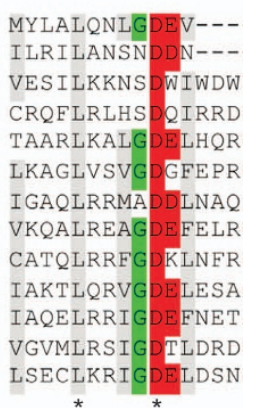

Figure 1. The Li-BH3AQP C-terminal region matches the BH3 consensus pattern. (a) Weblogo of the PS01259 pattern highlighting the strongly conserved residues leucine (L), aspartic acid (D) and glycine $(G)$ in positions 5, 9 and 10, respectively. (b) Alignment of Li-BH3AQP and representative $\mathrm{BH} 3$ domain sequences using the Clustal W software. Colored residues show highly conserved positions in the PS01259 pattern. Gray, hydrophobic residues; green, small residue (G); red, acidic residues. 
conformation, it could be accessible to Bcl-2-like proteins, although a portion of it might be partially embedded in the lipid membrane.

To assess whether the putative $\mathrm{BH} 3$ domain could fulfill the structural features required to interact with $\mathrm{Bcl}-\mathrm{X}_{\mathrm{L}}$, we analyzed our molecular model of Li-BH3AQP with an in-house software named CGRILL, ${ }^{32}$ which is formally similar to Goodford's program GRID. $^{33}$ cGRILL allows the identification of 3D affinity maps between the protein and a number of probes (i.e. $\mathrm{CH} 3, \mathrm{OH}$, etc.), therefore facilitating the interpretation of protein-protein energetics. As a test case for validation of the method, we chose the murine Bim fragment (residues 83-115) in complex with $\mathrm{BCl}-\mathrm{X}_{\mathrm{L}}$ (PDB i.d. 1PQ1). ${ }^{34}$ In this experimental structure, it can be seen that the side chains of four hydrophobic residues $(\mathrm{H} 1-\mathrm{H} 4)$, namely, Ile90, Leu94, lle97 and Phe101, each separated by a helical turn, are buried inside four well-defined pockets in Bcl- $\mathrm{X}_{\mathrm{L}}$. These regions are detected by the cGRILL hydrophobic probe as favorable for binding; the corresponding energy contours are displayed as a dark purple mesh in Figure 3. In addition, Bim orientates Tyr105 towards the less hydrophobic pocket $\mathrm{H} 5$. Another distinct region displaying favorable hydrogen-bonding properties is highlighted
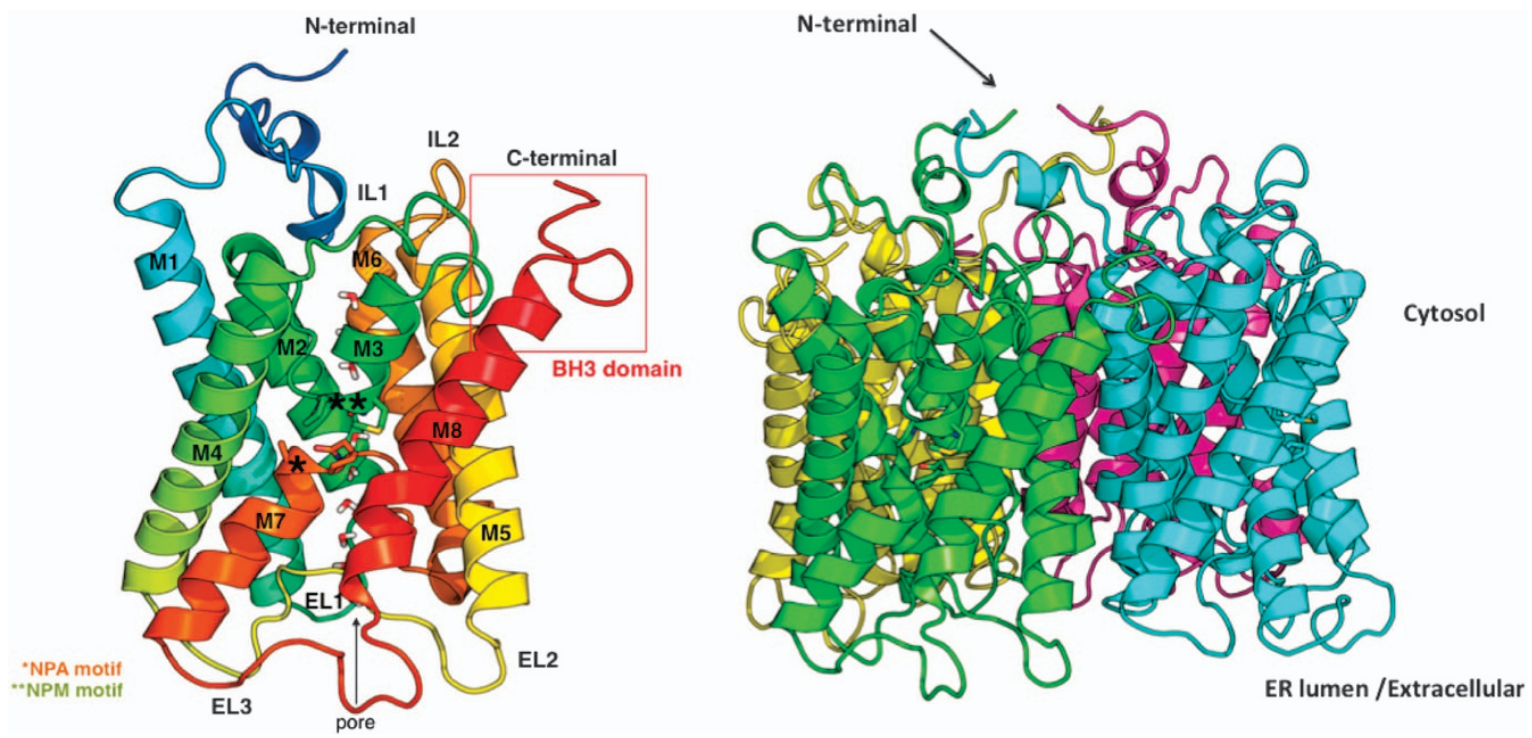

Figure 2. Homology model of monomeric (left) and tetrameric (right) Li-BH3AQP. Water molecules in the channel are shown as sticks. The putative $\mathrm{BH} 3$ domain is boxed. * indicates NPA aquaporin signature motif. ${ }^{*}$ indicates NPM motif.
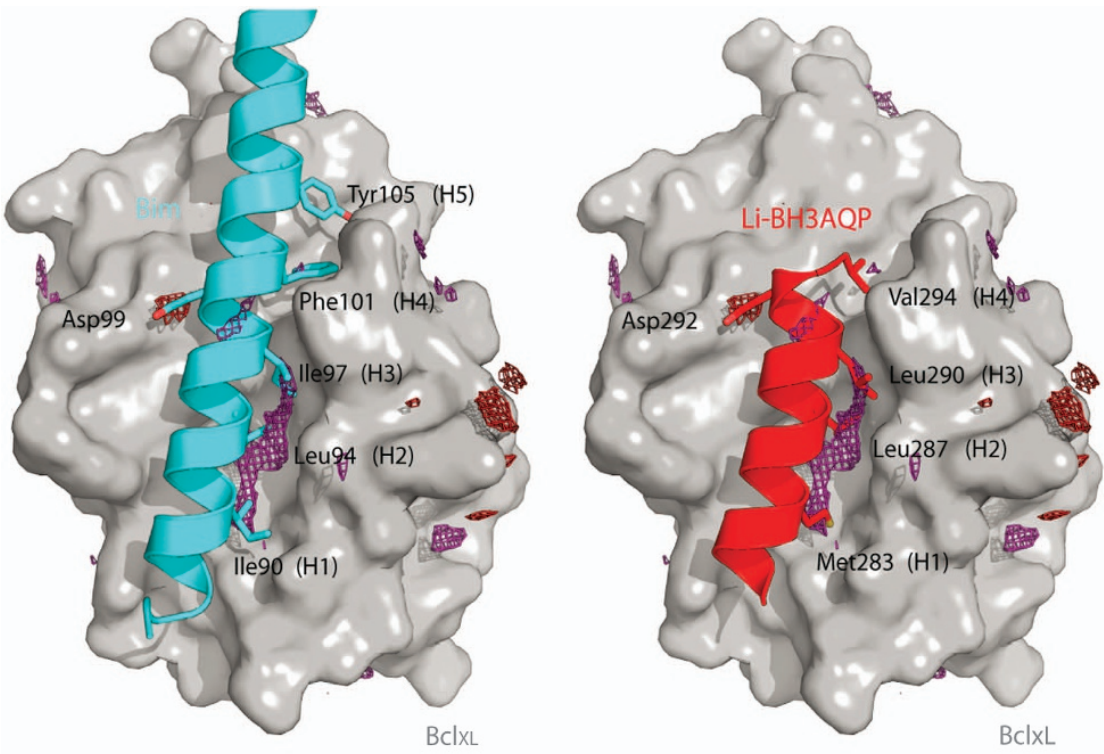

H1 Н2 Н3 H4 H5

$$
\begin{array}{lr}
\text { Li-BH3AQP } & 280-A S I M Y L A L Q N L G D E V-----294 \\
\text { Bim } & 87-E I R I A Q E L R R I G D E F N E T Y-105
\end{array}
$$

Figure 3. Interaction of Bim BH3 domain (left, cyan) and $\mathrm{Li}-\mathrm{BH} 3 \mathrm{AQP} \mathrm{C}$ terminus (right, red) with Bcl- $\mathrm{X}_{\mathrm{L}}$ (gray surface). Note the correspondence between the calculated affinity maps (dark purple, hydrophobic; red, carbonyl oxygen) on the surface of Bcl- $X_{L}$ and similarly spaced aminoacid side chains from Bim and $\mathrm{Li}-\mathrm{BH} 3 \mathrm{AQP} \mathrm{BH} 3$ domains. $\mathrm{H} 1$ to $\mathrm{H} 4$ hydrophobic positions in Bim $\mathrm{BH} 3$ domain are strictly conserved in Li-BH3AQP. 
by the carbonyl oxygen probe whose energy contour (red mesh in Figure 3) overlaps the side-chain carboxylate of Asp99. Our molecular model of the putative $\mathrm{Bcl}-\mathrm{X}_{\mathrm{L}}$ : $\mathrm{Li}-\mathrm{BH} 3 \mathrm{AQP}$ complex shows the hydrophobic side chains of Met283, Leu287, Leu290 and Val294 in the 283-MYLALQNLGDEV-294 stretch matching regions $\mathrm{H} 1-\mathrm{H} 4$ (underlined) in a similar manner to those of lle90, Leu94 lle97 and Phe101 in Bim, respectively, whereas the carboxylate of Asp292 occupies the same position as that of Asp99 of Bim.

\section{$\mathrm{Li}-\mathrm{BH} 3 \mathrm{AQP}$ binds to $\mathrm{BCl}-\mathrm{X}_{\mathrm{L}}$}

To assess whether Li-BH3AQP might be able to bind to antiapoptotic members of the $\mathrm{Bcl}-2$ family, we coexpressed a Myc-tagged version of $\mathrm{Li}-\mathrm{BH} 3 \mathrm{AQP}$ and a Flag-tagged version of human Bcl- $\mathrm{X}_{\mathrm{L}}$ in HEK293T cells. At $24 \mathrm{~h}$ after transfection, cells were lysed and expression of these two proteins was confirmed by western blot. Anti-Myc antibodies were used to immunoprecipitate Myc-tagged Li-BH3AQP and the presence of Flag-tagged $\mathrm{BCl}-\mathrm{X}_{\mathrm{L}}$ was confirmed by western blot with anti-Flag antibodies. The results shown in Figure $4 \mathrm{a}$ demonstrate that these two proteins bind to each other inside HEK293T cells.

The interaction between $\mathrm{Li}-\mathrm{BH} 3 \mathrm{AQP}$ and $\mathrm{BCl}-\mathrm{X}_{\mathrm{L}}$ was further demonstrated by the yeast two-hybrid system using $B c l-X_{L}$ (bound to the DNA-binding domain of GAL4) as the 'bait' and Li-BH3AQP (bound to the activation domain of GAL4) as the 'prey'. As shown in Figure 4b, Saccharomyces cerevisiae cells transfected with the pGBKT7-BCl- $X_{L}$ construct grow in the absence of tryptophan (-Trp) but not in the other three restrictive conditions ( - Leu; - Leu/ - Trp or -Leu/-Trp/-Ade/-His+x-a-Gal). Cells transfected with the pGADT7-Li-BH3AQP construct grow in the absence of leucine ( - Leu) but not in any other condition. Owing to the interaction of both proteins in the nuclei, cells transfected with both constructions grow in the absence of adenine or histidine. These cells were also able to hydrolyze $x$ - $a$-Gal.

\section{Reduced viability of HeLa cells expressing Li-BH3AQP}

It has been shown previously that transfection of human cells with DNA constructions that induce overexpression of proapoptotic $\mathrm{Bcl}-2$ family members causes a marked reduction in the number of viable cells. ${ }^{35}$ Accordingly, to test whether Li-BH3AQP may behave as a proapoptotic protein, the viability of HeLa cells transfected with a vector that allows expression of Li-BH3AQP ( $p C D N A 3 M y c-L i-$ $B H 3 A Q P$ ) was assayed and compared with that of cells transfected with the empty vector pCDNA3 (Figure 5). As a control, cells were also transfected with a sequence encoding the human Hrk proapoptotic protein ( $p C D N A 3 H r k)$. At $48 \mathrm{~h}$ after transfection, a significant reduction in the number of viable cells was observed for both Hrk- and Li-BH3AQP-expressing cells. Coexpression of $\mathrm{BCl}-\mathrm{X}_{\mathrm{L}} \quad\left(p C D N A 3 M y c-L i-B H 3 A Q P+p C D N A 3\right.$ Flag-Bcl- $\left.X_{L}\right)$ restored the viability of $\mathrm{Li}-\mathrm{BH} 3 \mathrm{AQP}$-expressing cells to values similar to that of the pCDNA3 control. These results support the notion that $\mathrm{Li}-\mathrm{BH} 3 \mathrm{AQP}$ behaves as a proapoptotic protein in HeLa cells.

Overexpression of $\mathrm{Li}-\mathrm{BH} 3 \mathrm{AQP}$ in $\mathrm{L}$. infantum cells

To obtain further insight into the activity of this protein in Leishmania parasites, we fused the sequence coding for an HA

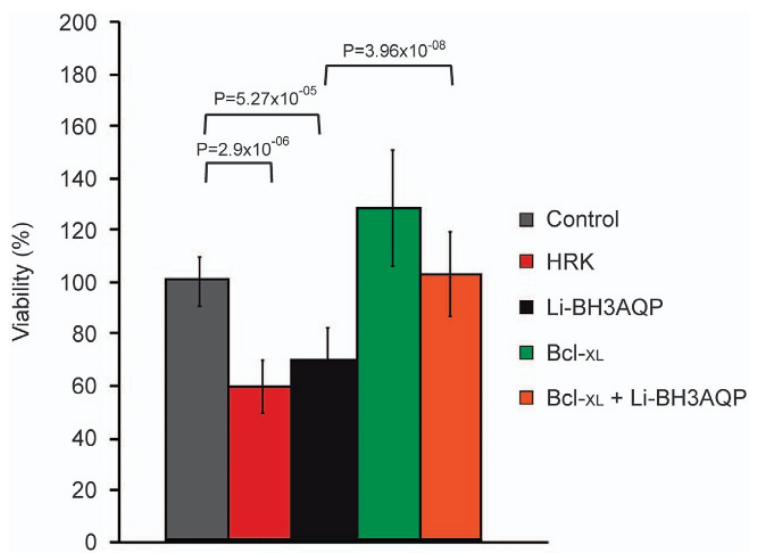

Figure 5. Li-BH3AQP promotes HeLa cell death. Cell viability was determined by the crystal violet method $48 \mathrm{~h}$ after transfection of HeLa cells with $500 \mathrm{ng}$ of $p C D N A 3$ (control), pCDNA3Hrk (HRK), pCDNA3Myc-Li-BH3AQP (Li-BH3AQP), pCDNA3Flag-BCl-X $X_{L}$ $\left(\mathrm{BCl}-\mathrm{X}_{\mathrm{L}}\right)$ and $p C D N A 3 F l a g-B C \mathrm{l}-\mathrm{X}_{\mathrm{L}}+p C D N A 3 M y c-L i-B H 3 A Q P\left(\mathrm{BCl}-\mathrm{X}_{\mathrm{L}}+\mathrm{Li}-\right.$ $\mathrm{BH} 3 \mathrm{AQP}$ ). Mean values of the samples are displayed in bar graphs. Error bars represent the $99.0 \%$ confidence intervals calculated for each mean; $n=12$.

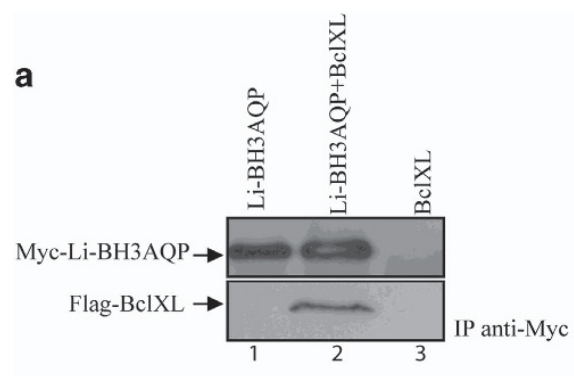

b

\begin{tabular}{|c|c|c|c|c|c|}
\hline \multirow[t]{2}{*}{ Construct } & \multicolumn{3}{|c|}{ Medium } & \multirow[b]{2}{*}{-Trp/-Leu /-Ade/-His +x- $\alpha$-Gal } & \multirow{5}{*}{$\begin{array}{l}\text { pGBKT7 Bcl-XL } \\
+ \\
\text { pGADLi-BH3AQP }\end{array}$} \\
\hline & -Leu & -Trp & -Leu/-Trp & & \\
\hline pGBKT7 Bcl $\mathrm{xL}_{\mathrm{L}}$ & - & + & - & - & \\
\hline pGAD Li-BH3AQP & + & $\cdot$ & - & - & \\
\hline $\begin{array}{c}\text { pGBKT7 Bcl }{ }_{x L}+p G A D \\
L i-B H 3 A Q P\end{array}$ & + & + & + & + & \\
\hline
\end{tabular}

Figure 4. Li-BH3AQP associates with BCl- $\mathrm{X}_{\mathrm{L}}$. (a) Myc-Li-BH3AQP and Flag-BCl- $\mathrm{X}_{\mathrm{L}}$ co-immunoprecipitation using an anti-Myc antibody in HEK293T whole-cell extracts. Immunoprecipitated fractions were blotted against an anti-Flag antibody to detect Flag-BCl- $X_{L}$. (b) Growth of the AH109 yeast strain transfected with $p G B K T 7-B C l-X_{L}, p G A D T 7-L i-B H 3 A Q P$ or co-transfected with both plasmids. Yeast growth was evaluated in different selective culture medium: (i) - Leu, (ii) - Trp, (iii) - Leu/ - Trp and (iv) - Leu/ - Trp/ - Ade/ - His+x-a-Gal. 
epitope at the $3^{\prime}$ end of $\angle i-B H 3 A Q P$ and then cloned it in the plRmcs-3 $(-)$ vector. Parasites transfected with this construction were selected in the presence of nourseothricin. No significant changes in growth rates were observed between parasites expressing the protein and those transfected with the empty vector. Similar results were obtained when expression of the protein was suddenly induced with tetracycline in $L$. tarentolae parasites (data not shown). The nourseothricin-resistant $L$. infantum promastigotes were incubated with antibodies against the HA epitope to detect the cellular localization of the tagged protein. According to the results shown in Figure 6, $L i-B H 3 A Q P$ is located in the perinuclear region and extends to some compartments inside the cells. This finding probably reflects its localization in the secretory pathway, as expected because of the predicted presence of multiple transmembrane regions.

The effect of overexpressing $\mathrm{Li}-\mathrm{BH} 3 \mathrm{AQP}$ in $L$. infantum promastigotes was evaluated in three different conditions: (i) incubation with staurosporine, (ii) nutrient deprivation and (iii) hypotonic stress. To estimate the relevance of the $\mathrm{BH} 3$ domain, wild-type (WT) parasites were also transfected with a vector containing the sequence encoding a $\mathrm{Li}-\mathrm{BH} 3 \mathrm{AQP}$ variant in which residues 287 and 292 belonging to the $\mathrm{BH} 3$ domain (positions 5 and 10 in the PS01259 motif) were replaced by Lys (Li-BH3AQP ${ }^{\mathrm{L} 287 \mathrm{~K} / \mathrm{D} 292 \mathrm{~K}}$ ). After selection with nourseothricin, these parasites were likewise incubated in the three conditions described above and survival rates were compared with those of parasites expressing WT Li-BH3AQP and with control parasites transfected with the empty vector.
Compared with control parasites, those overexpressing WT $\mathrm{Li}-\mathrm{BH} 3 \mathrm{AQP}$ displayed a significant reduction in the number of live promastigotes after staurosporine treatment at the two concentrations assayed (Figure $7 \mathrm{~b}$ ). In contrast, death rates similar to those of the control were observed in those parasites expressing $\mathrm{Li}-\mathrm{BH} 3 \mathrm{AQP} \mathrm{P}^{\mathrm{L} 287 \mathrm{~K} / \mathrm{D} 292 \mathrm{~K}}$, that is, the variant in which two key hydrophobic residues have been replaced with lysine. This finding strongly supports the relevance of the $\mathrm{BH} 3$ domain in the prodeath effect of Li-BH3AQP. Cell death could also be correlated with the percentages of hypoploid cells in the three populations. Following incubation with $10 \mu \mathrm{M}$ staurosporine, the percentage of hypoploid cells increased from 1 to $60 \%$ in parasites overexpressing WT $\mathrm{Li}-\mathrm{BH} 3 \mathrm{AQP}$, whereas in control and Li-BH3AQP ${ }^{\mathrm{L} 287 \mathrm{~K} / \mathrm{D} 292 \mathrm{~K}}$-overexpressing parasites it was below $43 \%$ (Figures $7 d$ and e). To ensure that the different behavior in the parasites that overexpress WT $\mathrm{Li}-\mathrm{BH} 3 \mathrm{AQP}$ is not restricted to staurosporine treatment, we analyzed survival rates in response to $24 \mathrm{~h}$ of incubation with antimycin $\mathrm{A}$. The results obtained for this drug are equivalent to those described for staurosporine (Supplementary Figure 2).

The same three populations of parasites were then incubated for $24 \mathrm{~h}$ in PBS to evaluate their behavior under nutrient-deprived conditions. Compared with controls, parasites overexpressing any of the two versions of the protein were partially protected against death, as indicated by the significant increase in the number of viable cells (Figure 7f). Finally, because of the demonstrated water transport activity of the $L$. donovani ortholog of $\mathrm{Li}-\mathrm{BH} 3 \mathrm{AQP},{ }^{25}$ the
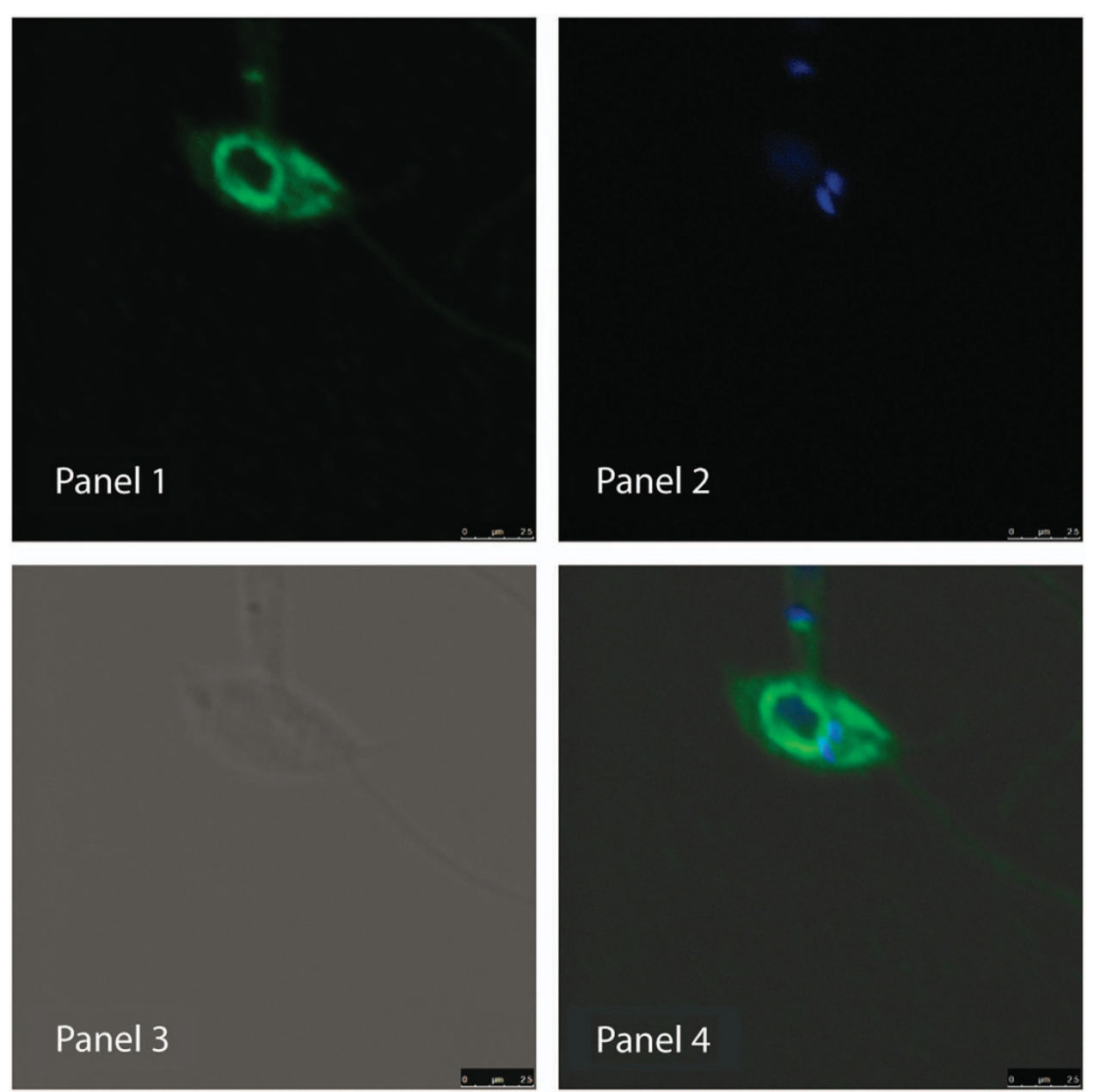

Figure 6. Cellular localization of Li-BH3AQP. (Panel 1) Confocal microscopy of Li-BH3AQP-overexpressing L. infantum promastigotes stained with anti-HA antibodies; (panel 2) DAPI (4',6-diamidino-2-phenylindole) staining; (panel 3) differential interference contrast (DIC); (panel 4) merged micrograph. 
parasites were kept for $3 \mathrm{~h}$ in PBS:water (50:50). Death induction as a consequence of hypotonic stress was diminished in parasites expressing either WT Li-BH3AQP or Li-BH3AQP L287K/D292K (Figure $7 \mathrm{~g}$ ). Taken together, analysis of the viability of the parasites under different stressing conditions reveals that Li-BH3AQP appears to have both prodeath and prosurvival roles.

\section{DISCUSSION}

Our research group and others have previously demonstrated that ectopic expression of antiapoptotic members of the $\mathrm{Bcl}-2$ family of proteins can interfere with death processes in protozoans. ${ }^{7}$ The antiapoptotic activity of these proteins relies mainly on their interaction with other proteins containing a $\mathrm{BH} 3$ domain. a

Li-BH3AQP

$\mathrm{Li}-\mathrm{BH} 3 \mathrm{AQP} \mathrm{P}_{\mathrm{L27 \pi K} \mathrm{D} 292 \mathrm{~K}}$

b

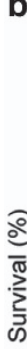

d

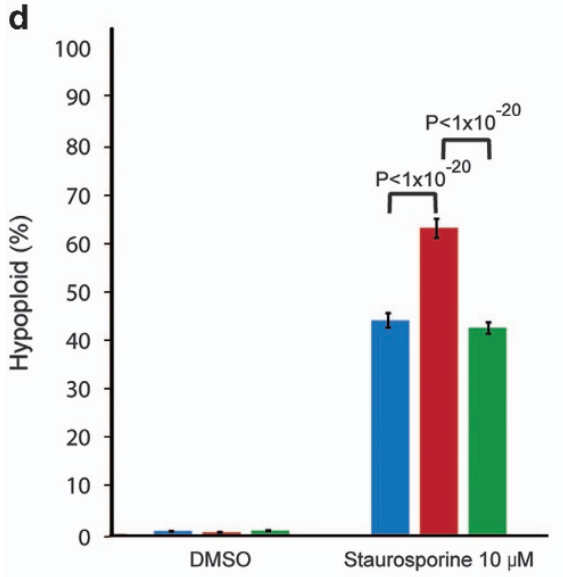

$\mathbf{f}$

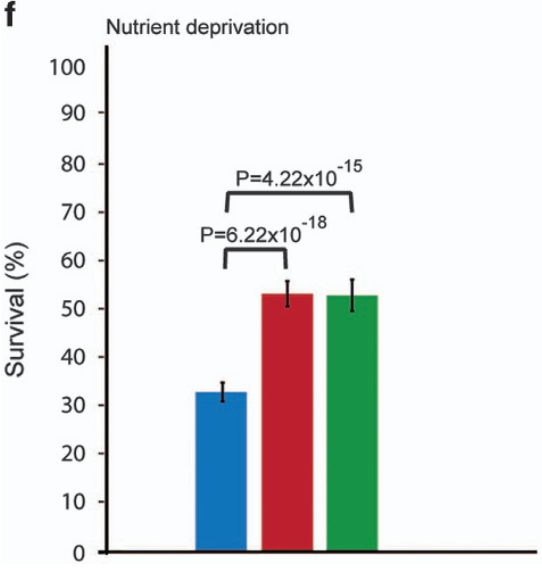

C

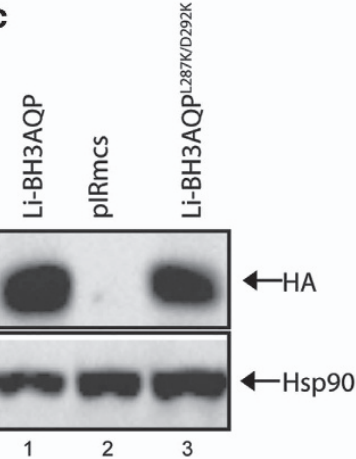

e
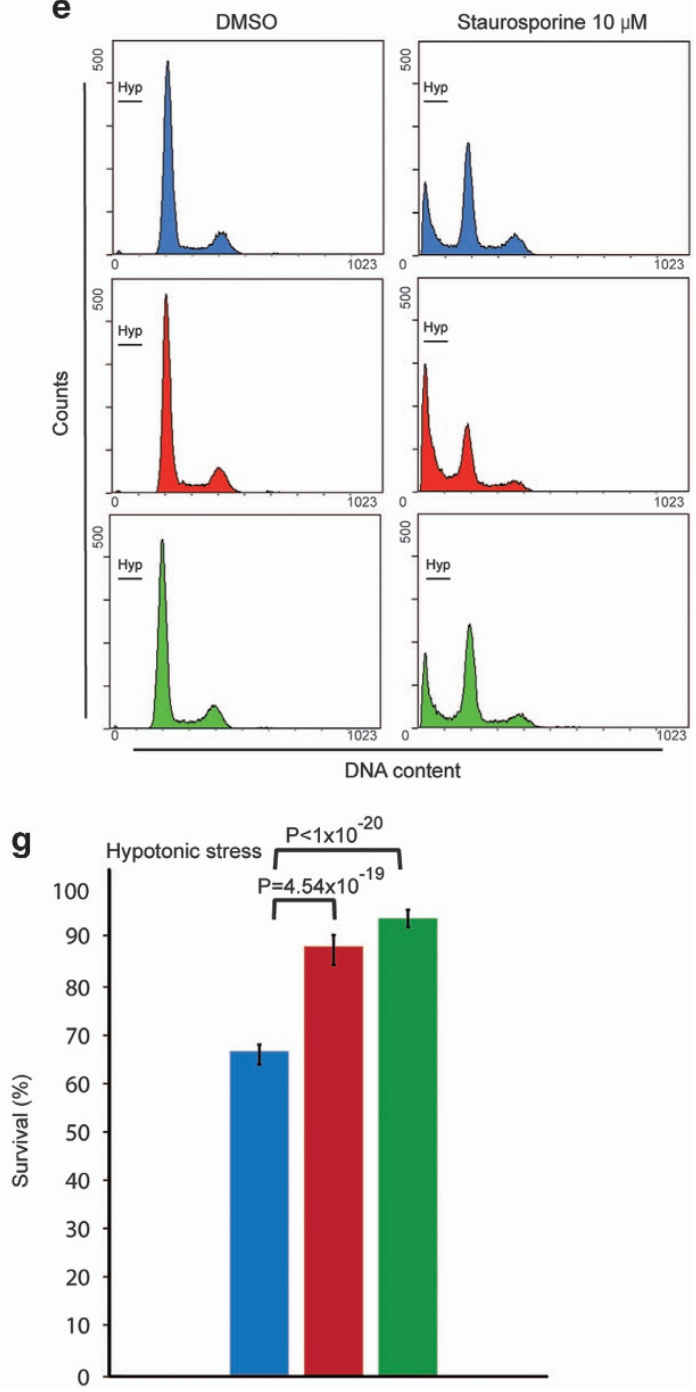
Accordingly, we initiated a research effort aimed at the identification of proteins containing $\mathrm{BH} 3$ domains in $L$. infantum. Even though there is no optimal bioinformatic procedure to reliably predict new $\mathrm{BH} 3$-containing proteins, ${ }^{36}$ the PHI-BLAST algorithm identified the MYLALQNLGDEV sequence as the second best match to the PS01259 signature motif in the Leishmania genome. Remarkably, this sequence is located at the $\mathrm{C}$ terminus of a pore-forming protein, specifically an aquaporin previously named AQP putative (XP_001465642.1), which is strictly conserved in the orthologs of L. donovani, L. major, L. mexicana, L. braziliensis and L. panamensis. Because of the presence of this putative $\mathrm{BH} 3$ domain, we propose to name the $L$. infantum protein $\mathrm{Li}-\mathrm{BH} 3 \mathrm{AQP}$. Even though our search in genome databases from trypanosomatids produced a few other interesting candidates containing putative $\mathrm{BH} 3$ motifs, we focused on Li-BH3AQP because of its ability to generate pores in plasma membranes. The results presented in Figure $4 a$ demonstrate coimmunoprecipitation of Li-BH3AQP and BCl- $\mathrm{X}_{\mathrm{L}}$ in HEK293T cells. This interaction was further supported in the two-hybrid system by the observed growth of $S$. cerevisiae cells transfected with $p G B K T 7-B C l-X_{L}$ and $p G A D T 7-L i-B H 3 A Q P$ in a reporter medium lacking histidine and adenine. Moreover, HeLa cells expressing Li-BH3AQP showed a marked reduction in viability $24 \mathrm{~h}$ after transfection, which was abrogated by coexpression of $\mathrm{BCl}-\mathrm{X}_{\mathrm{L}}$ (Figure 5). In contrast, overexpression of Li-BH3AQP in Leishmania promastigotes did not cause any reduction in viability under normal growth conditions. When parasites were challenged under different stressing conditions, either prodeath or prolife effects were detected depending on the nature of the stimulus. Overexpression of this protein sensitizes promastigotes to staurosporine or antimycin A, but is protective against nutrient withdrawal or hypotonic stress. Mutation of key residues in the $\mathrm{BH} 3$ domain abolishes the prodeath effect observed after treatment with any of these drugs but does not affect its prolife role. There is significant evidence to support an evolutionary process whereby key regulators of cell death in higher eukaryotes also contribute to vital cellular functions, for example cell cycle regulation, ${ }^{37}$ DNA damage responses, ${ }^{38,39}$ redox status, ${ }^{40}$ glucose or energy metabolism, ${ }^{41}$ ER physiology, ${ }^{42}$ and mitochondrial morphology and homeostasis. ${ }^{43,44}$ In all of these examples, BH3-containing proteins act as specialized stress sentinels that enable constant homeostatic quality control.

In common with Ybh3p from Saccharomyces, ${ }^{24} \mathrm{Li}-\mathrm{BH} 3 \mathrm{AQP}$ is likely to be a multimembrane-spanning protein that harbors a $\mathrm{BH} 3$ domain at the end of the terminal transmembrane segment. This particular location and the absence of the last three amino acids in the consensus $\mathrm{BH} 3$ sequence of both $\mathrm{Ybh} 3 p$ and $\mathrm{Li}-\mathrm{BH} 3 \mathrm{AQP}$ (Figure $1 \mathrm{~b}$ ) are unprecedented features in $\mathrm{BH} 3$-containing proteins. It has been argued that the $\mathrm{BH} 3$ sequence in $\mathrm{Ybh} 3 \mathrm{p}$ lacks conservation in orthologous proteins, ${ }^{36}$ but this is not the case for the motif in Li-BH3AQP, which is present in the sequences of L. donovani, L. major, L. mexicana, L. braziliensis and L. panamensis orthologs. Both the yeast and the Leishmania BH3-containing proteins bind to $B c l-X_{L}$ even though $B c l-X_{L}$ orthologs have not been found in any of these two species. This has been considered a relevant argument against the functional relevance of these $\mathrm{BH} 3$ motifs. However, as shown for the vaccinia virus protein A49, the 3D structural characteristics of $\mathrm{Bcl}-2$ family members can also be found in proteins with sequence identity as low as $8 \%{ }^{45}$ Therefore, proteins able to interact with $\mathrm{BH} 3$ domains may still be found in non-metazoan cells. Given that Leishmania parasites are intracellular and that protein migration from the parasites to the cell cytoplasm has already been demonstrated, ${ }^{46}$ it is also plausible that Li-BH3AQP might interact with antiapoptotic members of the host cells to interfere in their apoptotic programs. Experiments to analyze translocation of Li-BH3AQP from the parasites to the host cell are currently in progress.

In summary, our results demonstrate that: (i) a short amino-acid stretch in the C-terminal region of $\mathrm{Li}-\mathrm{BH} 3 \mathrm{AQP}$ displays structural properties that can account for the specific binding to $B c l-X_{L}$, (ii) $\mathrm{Li}-\mathrm{BH} 3 \mathrm{AQP}$ interacts with $\mathrm{BCl}-\mathrm{X}_{\mathrm{L}}$ both in yeast and mammalian cells, (iii) ectopic expression of Li-BH3AQP in HeLa cells causes a reduction in cell viability that can be reverted by overexpression of $\mathrm{BCl}-\mathrm{X}_{\mathrm{L}}$ and (iv) the $\mathrm{BH} 3$ domain in $\mathrm{Li}-\mathrm{BH} 3 \mathrm{AQP}$ is responsible for the reduced viability of $L$. infantum promastigotes treated with staurosporine or antimycin A.

Taken together, our results strongly suggest that Li-BH3AQP could well be the first non-enzymatic molecule involved in the cell death pathway in trypanosomatids. Moreover, our data support the view that protein-protein interactions involving $\mathrm{BH} 3$ domains might have appeared much earlier than expected during evolution even though they might not necessarily have been originally dedicated to orchestrate death processes.

\section{MATERIALS AND METHODS}

\section{Bioinformatics analyses}

Bioinformatics analysis and molecular modeling. The Li-BH3AQP DNA sequence was obtained from the kinetoplastid database http://tritrypdb.org (DNA i.d. XP_001465642.1). ${ }^{25}$ Any other DNA or protein sequences were obtained from the National Center for Biotechnology Information (NCBI). The PHI-BLAST algorithm was applied to search for putative BH3-containing sequences in the Leishmania genus. The central region (residues 5-12) of the BCl-2 family BH3 motif signature (L-[KARQ]-x-[IVAL]-G-D-[DESG]-[LIMFV] (Prosite entry PS01259) was used as the query sequence. After identification of a putative $\mathrm{BH} 3$ motif in the Leishmania genus, sequence alignments against other $\mathrm{BH} 3-$ containing proteins were performed using the Clustal $\mathrm{W}$ software (Conway Institute UCD, Dublin, Ireland). ${ }^{47}$

Phyre2. $0^{48}$ and Swiss-Model ${ }^{49}$ servers were used for the homology modeling of Li-BH3AQP (residues 1-294, UNIPROT i.d. A4I001). The crystal structures of Pp-Aqy1 (PDB entry 2W2E, 26\% i.d.; Fischer et al. ${ }^{28}$ ) and Mm-AqpM (PDB entry 2F2B, 29\% i.d.; Lee et al. ${ }^{29}$ ) were used as templates. Water molecules shown in Figure 2 were taken from $2 \mathrm{~F} 2 \mathrm{~B}$ and energy was minimized using sander (AmberTools15; AMBER) inside a channel of one $\mathrm{Li}-\mathrm{BH} 3 \mathrm{AQP}$ monomer. Affinity maps on the surface of $\mathrm{BCl}-\mathrm{X}_{\mathrm{L}}$ (PDB i.d. 1PQ1) ${ }^{34}$ were created using our in-house tool cGRILL. ${ }^{32}$ All molecules were visualized in PyMOL (DeLano, W. PyMOL, v.1.3).

Figure 7. Dual role of Li-BH3AQP on L. infantum promastigote survival under diverse death stimuli. Non-transfected parasites (control) and parasites overexpressing WT Li-BH3AQP or Li-BH3AQP $287 / \mathrm{K} / \mathrm{D} 292 \mathrm{~K}$ were incubated under different stressing conditions. Mean values of the samples are displayed in bar graphs. Error bars represent the $99.0 \%$ confidence intervals calculated for each mean. Cell viability was determined in all cases by flow cytometry using the PI exclusion method. (a) Amino-acid sequence alignment of the Li-BH3AQP native BH3 domain and the BH3 $3^{\mathrm{L} 287 \mathrm{~K} / \mathrm{D} 292 \mathrm{~K}}$ mutant. (b) Staurosporine treatment. Survival rates were determined under staurosporine concentrations of 5 and $10 \mu \mathrm{M}$. One percent DMSO was used as vehicle; $n=24$. (c) Western blot analysis of $L$. infantum promastigotes transfected with plRmcs-LiBH3AQP (Li-BH3AQP), with the empty vector (pIRmcs), or with plRmcs-Li-BH3AQP $P^{\mathrm{L} 287 \mathrm{~K} / \mathrm{D} 292 \mathrm{~K}}$ (Li-BH3AQP ${ }^{\mathrm{L} 287 \mathrm{~K} / \mathrm{D} 292 \mathrm{~K}}$ ). Anti-HA antibodies were used to detect the overexpressed proteins. Anti-Hsp90 antibodies were used as the loading control. (d) Quantification of hypoploid cells after $10 \mu \mathrm{M}$ staurosporine treatment; $n=24$. (e) DNA content of control and staurosporine-treated parasites analyzed by flow cytometry. The marker shows the hypoploid population. (f) Nutrient deprivation. Survival rates of parasites incubated for $24 \mathrm{~h}$ in phosphate-buffered saline (PBS). Percentages are normalized to parasites growing in complete medium; $n=18$. (g) Hypotonic stress. Survival rates were determined after incubation of the parasites for $3.5 \mathrm{~h}$ in water-diluted 50\% PBS. Rates are normalized to parasites incubated in $100 \%$ PBS; $n=24$ except for control parasites in which one data point was excluded from the statistical analysis $(n=23)$. 


\section{Reagents}

All reagents were obtained from Sigma-Aldrich (Saint Louis, MO, USA). Restriction enzymes, DNA polymerases, T4 DNA ligases, DNAse and alkaline phosphatase were obtained from Takara (Kusatsu, Japan), ThermoFisher (Waltham, MA, USA), Roche (Penzberg, Germany) and New England Biolabs (Ipswich, MA, USA). Gel purification and Maxi and miniprep kits were obtained from Qiagen (Hilden, Germany).

\section{Cells and culture conditions}

HeLa cells were kindly provided by Dr. Muñoz (Instituto de Investigaciones Biomédicas Alberto Sols CSIC-UAM, Madrid, Spain) and authenticated using the GenePrint 10 System (Promega Corporation, Fitchburg, WI, USA; $100 \%$ match with the reference strain). Cells were maintained in Dulbecco's modified Eagle's medium (DMEM; Sigma-Aldrich) supplemented with $10 \%$ fetal calf serum (FCS) (Gibco BRL Life Technologies, Paisley, UK), $100 \mathrm{U} / \mathrm{ml}$ penicillin (Gibco BRL Life Technologies), $100 \mu \mathrm{g} / \mathrm{ml}$ streptomycin (Gibco BRL Life Technologies) and $10 \mathrm{mM}$ HEPES at $37^{\circ} \mathrm{C}$ and $5 \% \mathrm{CO}_{2}$. Cells were tested for mycoplasma contamination.

HEK293T cells were kindly provided by Dr. Alonso (Centro de Biología Molecular 'Severo Ochoa' (CBMSO), Madrid, Spain) and maintained as monolayer cultures in $75-\mathrm{cm}^{2}$ tissue culture flasks in DMEM supplemented with $10 \%$ fetal bovine serum, $100 \mathrm{U} / \mathrm{ml}$ penicillin, $100 \mu \mathrm{g} / \mathrm{ml}$ streptomycin and $25 \mu \mathrm{g} / \mathrm{ml}$ amphotericin, in a humidified $5 \% \mathrm{CO}_{2} / 95 \%$ air incubator at $37^{\circ} \mathrm{C}$. This cell line was also authenticated using the GenePrint 10 System (Promega Corporation, Fitchburg, WI, USA; 94\% match with the reference strain). Cells were tested for mycoplasma contamination.

L. infantum promastigotes (M/CAN/ES/96/BCN150 MON-1), kindly provided by Dr. Alonso (CBMSO-Universidad Autónoma, Madrid, Spain), were grown in RPMI-1640 medium (Gibco, Paisley, UK) supplemented with $10 \%$ heat-inactivated $\mathrm{FCS}, 100 \mathrm{U} / \mathrm{ml}$ penicillin, $100 \mu \mathrm{g} / \mathrm{ml}$ streptomycin and $25 \mathrm{mM}$ HEPES at $26^{\circ} \mathrm{C}$. Recombinant parasites were obtained by electroporation with the plRmcs-3 plasmid containing the coding sequence of $\mathrm{Li}-\mathrm{BH} 3 \mathrm{AQP}$ or its mutated version Li-BH3AQP $\mathrm{L}^{\mathrm{L} 287 \mathrm{~K} / \mathrm{D} 292 \mathrm{~K}}$. The parasites were selected in nourseothricin-containing medium during 1 week and used for further experiments.

S. cerevisiae strain AH109 (Clontech, Mountain View, CA, USA), genotype: MATa, trp1-901, leu2-3, 112, ura3-52, his3-200, gal4D, gal80D, LYS2:: GAL1 UAS-

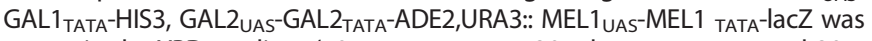
grown in the YPD medium (10 g yeast extract, $20 \mathrm{~g}$ bacto peptone and $20 \mathrm{~g}$ dextrose (glucose) at $30^{\circ} \mathrm{C}$ ). The cells were subsequently transformed by heat shock with different plasmids containing the sequences of human $\mathrm{BCl}-\mathrm{X}_{\mathrm{L}}$ or $\mathrm{Li}-\mathrm{BH} 3 \mathrm{AQP}$. The recombinant cells were maintained under selective pressure in solid agar medium.

\section{HeLa cells transfection and viability}

Transiently lipofectamine-transfected cells were used to study the overexpression effects of $\mathrm{Li}-\mathrm{BH} 3 \mathrm{AQP}$, as well as human $\mathrm{BCl}-\mathrm{X}_{\mathrm{L}}$ and HRK proteins. Five hundred microliters of a 50000 cells per $\mathrm{ml}$ suspension were placed in 24-well cell culture plates. After $24 \mathrm{~h}$ incubation, cell culture was removed and $250 \mu \mathrm{l}$ of a mixture of Lipofectamine (ThermoFisher), Optimem (ThermoFisher) and DNA (500 ng) was added to each well. Two hundred and fifty microliters of DMEM without antibiotics were subsequently added. Media were removed after $24 \mathrm{~h}$ and cells were incubated for 24 additional hours with complete medium. HeLa cell viability was determined by the crystal violet assay. Briefly, cells were stained with crystal violet $48 \mathrm{~h}$ after transfection with DNA constructions that allow expression of $\mathrm{Li}-\mathrm{BH} 3 \mathrm{AQP}, \mathrm{HRK}$ or $\mathrm{BCl}-\mathrm{X}_{\mathrm{L}}$. Color intensity was quantified using a spectrophotometer at $570 \mathrm{~nm}$.

\section{Protein electrophoresis and immunodetection}

A total of $10 \times 10^{6}$ parasites were lysed in $100 \mu \mathrm{l}$ of RIPA buffer and subsequently precipitated with four volumes of cold acetone at $-20^{\circ} \mathrm{C}$ during $60 \mathrm{~min}$. Precipitated protein was centrifuged at $18000 \times \mathrm{g}$ for $30 \mathrm{~min}$ and the protein pellet was solubilized in $8 \mathrm{M}$ urea. The protein concentration was determined by the BCA protein assay system (ThermoFisher). Each sample was boiled in Laemmli buffer before using it for SDS-PAGE analysis in 10\% acrylamide gels. For western blot analysis, proteins were transferred from the gels to a PVDF membrane in transfer buffer (25 mM Tris-HCl, $192 \mathrm{mM}$ glycine, 20\% methanol, 0.02\% SDS, $\mathrm{pH}$ 8.3). The membranes were first incubated for $1 \mathrm{~h}$ in a blocking solution consisting of TBS-T buffer ( $150 \mathrm{mM} \mathrm{NaCl}, 10 \mathrm{mM}$ Tris, $0.1 \%$ Tween, $\mathrm{pH}$ 8) supplemented with $5 \%$ of bovine serum albumin (Sigma-Aldrich) and then with anti-HA (1:250; Sigma-Aldrich; cat. no. H6908) or anti-Hsp90 (1:2500; Dr. Clos laboratory, Bernhard Nocht Institute for Tropical Medicine, Hamburg, Germany) antibodies during $16 \mathrm{~h}$ at $4{ }^{\circ} \mathrm{C}$ with shaking. An anti-rabbit (1:2000) antibody conjugated with HRP (SC-2004; Santa Cruz Biotechnology, Dallas, TX, USA) was used as the secondary antibody for HA detection and a goat anti-chicken IgY was used as the secondary antibody for Leishmania Hsp90 detection (SC-2428; Santa Cruz Biotechnology). Antibodies were recognized with ECL reagent (Thermo Scientific, Waltham, MA, USA).

\section{Co-immunoprecipitation}

$B C I-X_{L}$ and $L i-B H 3 A Q P$ genes were cloned into PCDNA3 plasmids fused either with Flag or Myc tags, respectively. HEK293T cells were collected after transient transfection with the different combinations of constructions for $24 \mathrm{~h}$ and used for whole-cell extract preparation. Immunoprecipitation was carried out using a resin-conjugated antibody (anti-myc) complex (A7470$1 \mathrm{ml}$; Sigma, St Louis, MO, USA). After extensive washing steps, the immunoprecipitated fraction was used for western blotting using an antiFlag antibody to detect BCl-X (monoclonal ANTI-FLAG M2, Clone M2; F3165; Sigma-Aldrich) and an anti-myc antibody to detect Li-BH3AQP (sc40; Santa Cruz Biotechnology, Dallas, Texas, USA).

\section{Yeast two-hybrid assay}

In this assay, human $\mathrm{BCl}-\mathrm{X}_{\mathrm{L}}$ was used as a bait and Li-BH3AQP as a prey. Briefly, when both bait and prey proteins have a physical interaction, a Gal4 transcription factor activates transcription of four reporter genes (ADE2, HIS3, LacZ and MEL1) allowing cellular growth in a minimal medium lacking histidine and adenine. Furthermore, the MEL1 gene encodes for $a$-galactosidase that allows transformation of the chromogenic substrate $\mathrm{x}$ - $\mathrm{a}$-Gal into a blue product. $\mathrm{BCl}-\mathrm{X}_{\mathrm{L}}$ was cloned in the BpGBK-T7 plasmid that allows cell growth in a medium lacking the Trp. Li-BH3AQP was cloned in the pGADT7 plasmid that allows cell growth in a medium lacking the Leu. To confirm expression of both proteins, a medium lacking Trp and Leu (-Trp/-Leu) was used to select the cotransformed cells. Finally, some of these colonies were plated into a agar medium lacking Trp, Leu, His and Ade in the presence of the chromogenic substrate $x-a-G a l$.

\section{Confocal microscopy}

Logarithmic growth phase parasites were fixed using a solution containing $2 \%$ paraformaldehyde and permeabilised with $0.1 \%$ Triton X-100. Anti-HA (Sigma-Aldrich; cat. no. H6908; 1:50) antibody was used to determine the localization of Li-BH3AQP and DAPI was used to visualize the nuclei. Alexa Fluor 488 anti-rabbit antibody was used as secondary antibody (Life Technologies). All preparations were mounted using ProLong Gold Antifade Reagent (Life Technologies) and analyzed using a Leica TCS SL Microscope (Leica Microsystems GmbH, Wetzlar, Germany).

\section{Drug treatment of the parasites}

Staurosporine and antimycin A treatments of promastigotes were performed during the logarithmic growth phase at the drug concentrations indicated in the figures for $24 \mathrm{~h}$. L. infantum promastigotes were diluted in $10 \mathrm{ml}$ of cell culture medium at $2 \times 10^{6}$ cells per ml. After $24 \mathrm{~h}$, parasites were diluted again to $2 \times 10^{6}$ cells per $\mathrm{ml}$ and $200 \mu \mathrm{l}$ aliquots were placed in 96-well cell culture plates. Two microliters of a stock solution of staurosporine or $3 \mu \mathrm{l}$ of a stock solution of antimycin A were added to each well. Equivalent volumes of DMSO were added to controls. After $24 \mathrm{~h}$ of incubation at $26^{\circ} \mathrm{C}$, parasite viability was evaluated by flow cytometry by the propidium iodide (PI) exclusion method. Briefly, treated parasites were stained for $10 \mathrm{~min}$ with $10 \mu \mathrm{g} / \mathrm{ml} \mathrm{PI}$. The number of $\mathrm{PI}$ - parasites was determined in a Beckman Coulter FC500 flow cytometer (Brea, CA, USA).

\section{Nutrient deprivation}

L. infantum promastigotes were diluted in $10 \mathrm{ml}$ of cell culture medium at $2 \times 10^{6}$ cells per ml. After $24 \mathrm{~h}$, cells were counted and, for each sample, 600000 parasites were centrifuged at $1000 \times g$ for $5 \mathrm{~min}$. Pellets were resuspended in $300 \mu \mathrm{l}$ of cell culture medium or PBS and $200 \mu \mathrm{l}\left(2 \times 10^{6}\right.$ promastigotes per $\mathrm{ml}$ ) were dispensed in $96-$ well cell culture plates. After $24 \mathrm{~h}$ of incubation, parasite viability was evaluated by flow cytometry by the PI exclusion method. 


\section{Hypotonic stress}

L. infantum promastigotes were diluted in $10 \mathrm{ml}$ of cell culture medium at $2 \times 10^{6}$ cells per ml. After $24 \mathrm{~h}$, cells were counted, centrifuged and resuspended at $32 \times 10^{6}$ parasites per $\mathrm{ml}$ in PBS. Fifty microliters of this suspension $\left(1.6 \times 10^{6}\right.$ parasites) were placed in 96 -well cell culture plates and $150 \mu \mathrm{l}$ of $33 \%$ PBS diluted in sterilized $\mathrm{H}_{2} \mathrm{O}$ was added to reach a final PBS concentration of $50 \%$. After $3.5 \mathrm{~h}$ of incubation, parasite viability was evaluated by flow cytometry by the PI exclusion method.

\section{DNA content analysis by flow cytometry}

L. infantum promastigotes were diluted in $10 \mathrm{ml}$ of cell culture medium at $2 \times 10^{6}$ cells per ml. After $24 \mathrm{~h}$, parasites were diluted again to $2 \times 10^{6}$ cells per $\mathrm{ml}$ and $2 \mathrm{ml}$ aliquots were placed in wells of 24 -well cell culture plates. Twenty microliters of a stock solution of staurosporine $(1 \mathrm{mM})$ were added to each well. Parasites were centrifuged at $1000 \times g$ for $5 \mathrm{~min}$, the pellet was resuspended in $100 \mu \mathrm{l}$ of ice-cold PBS and $700 \mu \mathrm{l}$ of $80 \%$ ethanol at $-20^{\circ} \mathrm{C}$ were added and then parasites were incubated overnight at $-20^{\circ} \mathrm{C}$. After incubation, the parasites were washed with $800 \mu \mathrm{l}$ of PBS, pelleted at $1000 \times g$ and then resuspended in $400 \mu \mathrm{l}$ of PBS $/ 10 \mu \mathrm{g} / \mathrm{ml}$ $\mathrm{Pl} / 50 \mu \mathrm{g} / \mathrm{ml} \mathrm{RNAse}$ and incubated for $30 \mathrm{~min}$ at $37^{\circ} \mathrm{C}$. The parasites were then analyzed for PI fluorescence in a Beckman Coulter FC500 flow cytometer (Brea, CA, USA).

\section{Statistical analysis}

Standardized skewness and standardized kurtosis were analyzed to determine whether the samples come from normal distributions. To ensure normality, values of these statistics were always tested to be within the range of -2 to +2 . Kolmogorov-Smirnov test was also run to determine whether the samples could be adequately modeled by a normal distribution.

Once the normal distribution of data was checked, the Welch's unequal variances $t$-test was used to compare means of different samples. ${ }^{50,51}$ This test is designed for normally distributed samples that might have unequal variances. The Excel T.Test function with the specific parameters for a twotailed analysis of heteroskedastic independent samples was used to compute $P$-values and decide if the null hypothesis (mean $1=$ mean 2 ) can be rejected. Even though it was not needed, variances were checked for similarity in all samples. The number of independent replicates $(n)$ was adjusted to be the highest possible without increasing the risk of human errors. The $n$ value is indicated in the figure legends. Experiments were carried out in three different days and the replicates were equally distributed among them.

Mean values of the samples are displayed in bar graphs. Error bars represent the $99.0 \%$ confidence intervals calculated for each mean. Data points out from the range of the mean \pm 3 S.D. were excluded from the analysis. Among all the samples analyzed, only one data point obtained during the hypotonic stress was found to be out of this range and, consequently, was omitted. This fact is indicated in the legend to Figure $7 \mathrm{~g}$.

Groups of numerical data are also depicted in standard box-and-whisker plots in the Supplementary Material Section (Supplementary Figure S3). Statgraphics centurion XVII program was used for calculation of the mean confidence intervals and for boxplot representations.

\section{ACKNOWLEDGEMENTS}

We thank Dr. Slavica Masina for careful reading of the manuscript and M Isabel PérezMorgado and Kilian Gutiérrez-Viñas for technical assistance. CMG thanks the Spanish MEC/MICINN for his FPI fellowship. This work was supported by Grants SAF201239760-C02, and S-2010/BMD-2457 (BIPEDD-2) from MINECO and Comunidad de Madrid, respectively (to FG and AJR), Junta de Comunidades de Castilla la Mancha POII10-0180-7897 (to AJR) and FNRS N.3100A0-116665/1 IZ70Z0-131421 (to NF).

\section{COMPETING INTERESTS}

The authors declare no conflict of interest.

\section{REFERENCES}

1 Ameisen JC, Idziorek T, Billaut-Mulot O, Loyens M, Tissier JP, Potentier A et al. Apoptosis in a unicellular eukaryote (Trypanosoma cruzi): implications for the evolutionary origin and role of programmed cell death in the control of cell proliferation, differentiation and survival. Cell Death Differ 1995; 2: 285-300.

2 Welburn SC, Dale C, Ellis D, Beecroft R, Pearson TW. Apoptosis in procyclic Trypanosoma brucei rhodesiense in vitro. Cell Death Differ 1996; 3: 229-236.
3 Madeo F, Engelhardt S, Herker E, Lehmann N, Maldener C, Proksch A et al. Apoptosis in yeast: a new model system with applications in cell biology and medicine. Curr Genet 2002; 41: 208-216.

4 Moharikar S, D'Souza JS, Kulkarni AB, Rao BJ. Apoptotic-like cell death pathway is induced in unicellular chlorophyte Chlamydomonas reinhardtii (chlorophyceae) cells following UV irradiation: detection and functional analyses. J Phycol 2006; 42: 423-433.

5 Figarella K, Rawer M, Uzcategui NL, Kubata BK, Lauber K, Madeo F et al. Prostaglandin D2 induces programmed cell death in Trypanosoma brucei bloodstream form. Cell Death Differ 2005; 12: 335-346.

6 Zangger H, Mottram JC, Fasel N. Cell death in Leishmania induced by stress and differentiation: programmed cell death or necrosis? Cell Death Differ 2002; 9: 1126-1139.

7 Alzate JF, Alvarez-Barrientos A, Gonzalez VM, Jimenez-Ruiz A. Heat-induced programmed cell death in Leishmania infantum is reverted by $\mathrm{Bcl}-\mathrm{X}(\mathrm{L})$ expression. Apoptosis 2006; 11: 161-171.

8 Al-Olayan EM, Williams GT, Hurd H. Apoptosis in the malaria protozoan, Plasmodium berghei: a possible mechanism for limiting intensity of infection in the mosquito. Int J Parasitol 2002; 32: 1133-1143.

9 Arambage SC, Grant KM, Pardo I, Ranford-Cartwright L, Hurd H. Malaria ookinetes exhibit multiple markers for apoptosis-like programmed cell death in vitro. Parasit Vectors 2009; 2: 32.

10 Meslin B, Barnadas C, Boni V, Latour C, De Monbrison F, Kaiser K et al. Features of apoptosis in Plasmodium falciparum erythrocytic stage through a putative role of PfMCA1 metacaspase-like protein. J Infect Dis 2007; 195: 1852-1859.

11 Picot S, Burnod J, Bracchi V, Chumpitazi BF, Ambroise-Thomas P. Apoptosis related to chloroquine sensitivity of the human malaria parasite Plasmodium falciparum. Trans R Soc Trop Med Hyg 1997; 91: 590-591.

12 Reece SE, Pollitt LC, Colegrave N, Gardner A. The meaning of death: evolution and ecology of apoptosis in protozoan parasites. PLoS Pathog 2011; 7: e1002320.

13 van Zandbergen G, Luder CG, Heussler V, Duszenko M. Programmed cell death in unicellular parasites: a prerequisite for sustained infection? Trends Parasitol 2010; 26: 477-483.

14 Proto WR, Coombs GH, Mottram JC. Cell death in parasitic protozoa: regulated or incidental? Nat Rev Microbiol 2012; 11: 58-66.

15 Bosedasgupta S, Das BB, Sengupta S, Ganguly A, Roy A, Dey S et al. The caspaseindependent algorithm of programmed cell death in Leishmania induced by baicalein: the role of LdEndoG, LdFEN-1 and LdTatD as a DNA 'degradesome'. Cell Death Differ 2008; 15: 1629-1640.

16 Gannavaram S, Vedvyas C, Debrabant A. Conservation of the pro-apoptotic nuclease activity of endonuclease $\mathrm{G}$ in unicellular trypanosomatid parasites. J Cell Sci 2008; 121: 99-109.

17 Rico E, Alzate JF, Arias AA, Moreno D, Clos J, Gago F et al. Leishmania infantum expresses a mitochondrial nuclease homologous to EndoG that migrates to the nucleus in response to an apoptotic stimulus. Mol Biochem Parasitol 2009; 163: 28-38.

18 Lee N, Gannavaram S, Selvapandiyan A, Debrabant A. Characterization of metacaspases with trypsin-like activity and their putative role in programmed cell death in the protozoan parasite Leishmania. Eukaryot Cell 2007; 6: 1745-1757.

19 Zalila H, Gonzalez IJ, El-Fadili AK, Delgado MB, Desponds C, Schaff C et al. Processing of metacaspase into a cytoplasmic catalytic domain mediating cell death in Leishmania major. Mol Microbiol 2011; 79: 222-239.

20 Casanova M, Gonzalez IJ, Sprissler C, Zalila H, Dacher M, Basmaciyan L et al. Implication of different domains of the Leishmania major metacaspase in cell death and autophagy. Cell Death Dis 2015; 6: e1933.

21 Silva RD, Manon S, Goncalves J, Saraiva L, Corte-Real M. Modulation of Bax mitochondrial insertion and induced cell death in yeast by mammalian protein kinase Calpha. Exp Cell Res 2011; 317: 781-790.

22 Vander Heiden MG, Choy JS, VanderWeele DJ, Brace JL, Harris MH, Bauer DE et al. $\mathrm{Bcl}-\mathrm{x}(\mathrm{L})$ complements Saccharomyces cerevisiae genes that facilitate the switch from glycolytic to oxidative metabolism. J Biol Chem 2002; 277: 44870-44876.

23 Arnoult D, Akarid K, Grodet A, Petit PX, Estaquier J, Ameisen JC. On the evolution of programmed cell death: apoptosis of the unicellular eukaryote Leishmania major involves cysteine proteinase activation and mitochondrion permeabilization. Cell Death Differ 2002; 9: 65-81.

24 Buttner S, Ruli D, Vogtle FN, Galluzzi L, Moitzi B, Eisenberg T et al. A yeast BH3-only protein mediates the mitochondrial pathway of apoptosis. EMBO J 2011; 30: 2779-2792.

25 Biyani N, Mandal S, Seth C, Saint M, Natarajan K, Ghosh I et al. Characterization of Leishmania donovani aquaporins shows presence of subcellular aquaporins similar to tonoplast intrinsic proteins of plants. PLoS One 2011; 6: e24820.

26 Schneider TD, Stephens RM. Sequence logos: a new way to display consensus sequences. Nucleic Acids Res 1990; 18: 6097-6100.

27 PROSITE. Available at: http://prosite.expasy.org/PS01259. Last accessed date 1 May 2016. 
28 Fischer G, Kosinska-Eriksson U, Aponte-Santamaría C, Palmgren M, Geijer C, Hedfalk $\mathrm{K}$ et al. Crystal structure of a yeast aquaporin at $1.15 \AA$ reveals a novel gating mechanism. PLoS Biol 2009; 7: e1000130.

29 Lee JK, Kozono D, Remis J, Kitagawa Y, Agre P, Stroud RM. Structural basis for conductance by the archaeal aquaporin AqpM at 1.68A. Proc Natl Acad Sci USA 2005; 102: 18932-18937.

30 Wree D, Wu B, Zeuthen T, Beitz E. Requirement for asparagine in the aquaporin NPA sequence signature motifs for cation exclusion. FEBS $J$ 2011; 278: 740-748.

31 Newby ZE, O'Connell J III, Robles-Colmenares Y, Khademi S, Miercke L, Stroud RM. Crystal structure of the aquaglyceroporin PfAQP from the malarial parasite Plasmodium falciparum. Nat Struct Mol Biol 2008; 15: 619-625.

32 Gago F. Available at: http://farmamol.uah.es. Last accessed date 1 May 2016.

33 Goodford PJ. A computational procedure for determining energetically favorable binding sites on biologically important macromolecules. J Med Chem 1985; 28: 849-857.

34 Liu X, Dai S, Zhu Y, Marrack P, Kappler JW. The structure of a Bcl-xL/Bim fragment complex: implications for Bim function. Immunity 2003; 19: 341-352.

35 Inohara N, Ding L, Chen S, Nunez G. Harakiri, a novel regulator of cell death, encodes a protein that activates apoptosis and interacts selectively with survivalpromoting proteins $\mathrm{BCl}-2$ and $\mathrm{BCl}-\mathrm{X}(\mathrm{L})$. EMBO J 1997; 16: 1686-1694.

36 Aouacheria A, Rech de Laval V, Combet C, Hardwick JM. Evolution of Bcl-2 homology motifs: homology versus homoplasy. Trends Cell Biol 2013; 23: 103-111.

37 Zinkel S, Gross A, Yang E. BCL2 family in DNA damage and cell cycle control. Cell Death Differ 2006; 13: 1351-1359.

38 Zinkel SS, Hurov KE, Ong C, Abtahi FM, Gross A, Korsmeyer SJ. A role for proapoptotic BID in the DNA-damage response. Cell 2005; 122: 579-591.

39 Kamer I, Sarig R, Zaltsman Y, Niv H, Oberkovitz G, Regev L et al. Proapoptotic BID is an ATM effector in the DNA-damage response. Cell 2005; 122: 593-603.

40 Kowaltowski AJ, Fiskum G. Redox mechanisms of cytoprotection by Bcl-2. Antioxid Redox Signal 2005; 7: 508-514.

41 Danial NN, Gramm CF, Scorrano L, Zhang CY, Krauss S, Ranger AM et al. BAD and glucokinase reside in a mitochondrial complex that integrates glycolysis and apoptosis. Nature 2003; 424: 952-956.
42 Hetz C, Glimcher L. The daily job of night killers: alternative roles of the BCL-2 family in organelle physiology. Trends Cell Biol 2008; 18: 38-44.

43 Vander Heiden MG, Thompson CB. BCl-2 proteins: regulators of apoptosis or of mitochondrial homeostasis? Nat Cell Biol 1999; 1: E209-E216.

44 Hardwick JM, Chen YB, Jonas EA. Multipolar functions of BCL-2 proteins link energetics to apoptosis. Trends Cell Biol 2012; 22: 318-328.

45 Neidel S, Maluquer de Motes C, Mansur DS, Strnadova P, Smith GL, Graham SC. Vaccinia virus protein $\mathrm{A} 49$ is an unexpected member of the B-cell Lymphoma (BCl)-2 protein family. J Biol Chem 2015; 290: 5991-6002.

46 Lambertz U, Silverman JM, Nandan D, McMaster WR, Clos J, Foster LJ et al. Secreted virulence factors and immune evasion in visceral leishmaniasis. J Leukoc Biol 2012; 91: 887-899.

47 Larkin MA, Blackshields G, Brown NP, Chenna R, McGettigan PA, McWilliam H et al. Clustal W and Clustal X version 2.0. Bioinformatics 2007; 23: 2947-2948.

48 Kelley LA, Mezulis S, Yates CM, Wass MN, Sternberg MJE. The Phyre2 web portal for protein modeling, prediction and analysis. Nat Protocols 2015; 10: 845-858.

49 Biasini M, Bienert S, Waterhouse A, Arnold K, Studer G, Schmidt T et al. SWISS-MODEL: modelling protein tertiary and quaternary structure using evolutionary information. Nucleic Acids Res 2014; 42: W252-W258.

50 Ruxton GD. The unequal variance $t$-test is an underused alternative to Student's $t$-test and the Mann-Whitney $U$ test. Behav Ecol 2006; 17: 688-690.

51 Moser BK, Stevens GR. Homogeneity of variance in the two-sample means test. Am Stat 1992; 46: 19-21.

(i) This work is licensed under a Creative Commons Attribution 4.0 International License. The images or other third party material in this article are included in the article's Creative Commons license, unless indicated otherwise in the credit line; if the material is not included under the Creative Commons license, users will need to obtain permission from the license holder to reproduce the material. To view a copy of this license, visit http://creativecommons.org/licenses/ by/4.0/

(c) The Author(s) 2016

Supplementary Information accompanies the paper on the Cell Death and Discovery website (http://www.nature.com/cddiscovery) 